\title{
DYSCEPHALIA MANDIBULO-OCULO-FACIALIS*
}

\author{
(HALLERMANN-STREIFF SYNDROME)
}

BY

\author{
D. HOEFNAGEL and K. BENIRSCHKE
}

From the Departments of Pathology and Pediatrics, Dartmouth Medical School, the Department of Pediatrics, Hitchcock Clinic, Hanover, New Hampshire, the Department of Pediatrics, Boston City Hospital, Boston, Massachusetts, and the Laconia State School, Laconia, New Hampshire, U.S.A.

(RECEIVED FOR PUBLICATION APRIL 14, 1964)

The classification of the cranio-facial dysostoses is hampered by the great heterogeneity of the various developmental anomalies of face and skull. The purpose of this paper is to describe three cases of one of the rarer of these entities, dyscephalia mandibulooculo-facialis. Cases of this syndrome have been described under a variety of names: 'Vogelgesicht und Cataracta congenita' (Hallermann, 1948); 'Dysmorphie mandibulo-faciale (tête d'oiseau) et altérations oculaires' (Streiff, 1950); 'Dyskephalie mit Cataracta congenita und Hypotrichose' (Ullrich and Fremerey-Dohna, 1953); 'Hallermann-Streiff syndrome' (Falls and Schull, 1960); 'Syndrome dyscéphalique de François' (Carones, 1961); 'Dyscephalia mandibulo-oculo-facialis' (Waardenburg, Franceschetti, and Klein, 1961).

TABLE

RELEVANT DATA IN THE CASES

\begin{tabular}{c|c|c|c|c}
\hline $\begin{array}{c}\text { Case } \\
\text { No. }\end{array}$ & $\begin{array}{c}\text { Age of Parents } \\
\text { at Time of } \\
\text { Birth of Child } \\
\text { (yr.) }\end{array}$ & Pregnancy & $\begin{array}{c}\text { Birth- } \\
\text { weight } \\
\text { (kg.) }\end{array}$ & $\begin{array}{c}\text { Teeth } \\
\text { Present } \\
\text { at } \\
\text { Birth }\end{array}$ \\
\hline 1 & $\begin{array}{c}\text { Fa: }: 36 \\
\text { Mo: } 37\end{array}$ & Full-term & $2 \cdot 4$ & Yes \\
\hline 2 & $\begin{array}{c}\text { Fa: }: 35 \\
\text { Mo: }: 33\end{array}$ & Full-term & $2 \cdot 6$ & Yes \\
\hline 3 & $\begin{array}{c}\text { Fa: }: 39 \\
\text { Mo: 34 }\end{array}$ & 7 months & 1.91 & Yes \\
\hline
\end{tabular}

Case Reports

Some relevant data of the three cases have been summarized in the Table. In none of the families was there evidence of consanguinity or familial disorders. The pregnancies and deliveries had a normal course in all three cases. Tests for galactosaemia and congenital lues were negative in all 3 cases.

* This study was supported by Grant GM 10210 of the United States Public Health Service and a Grant from the Charles H. Hood Dairy Foundation.
Case 1. White female examined at the age of 1 year because of nystagmus. The child weighed $5 \cdot 35 \mathrm{~kg}$.; severe retardation of growth and development was evident. The head was small and flattened posteriorly (Fig. 1). The eyes were examined under anaesthesia: both globes were small, the corneae were clear, but small; the anterior chambers were of average depth, there were extensive posterior synechiae, no details of the ocular fundi were visible because of dense cataracts. The eyelids were lax and the tarsal plates missing or rudimentary; the lacrimal punctae were present. Tear secretion was normal. Eyebrows and eyelashes were absent. When examined at the age of 8 years (Fig. 2) her weight was $11 \mathrm{~kg}$. and height $102 \mathrm{~cm}$. The head was brachycephalic with a circumference of $47 \mathrm{~cm}$. and prominent frontal and parietal eminences; there was sparse growth of fine blond hair restricted to the posterior part of the head; the

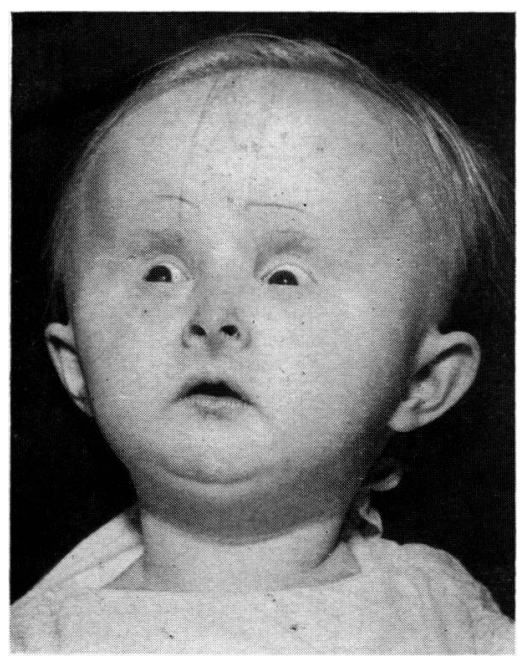

FIG. 1.-Appearance of Case 1 at the age of 1 year. 

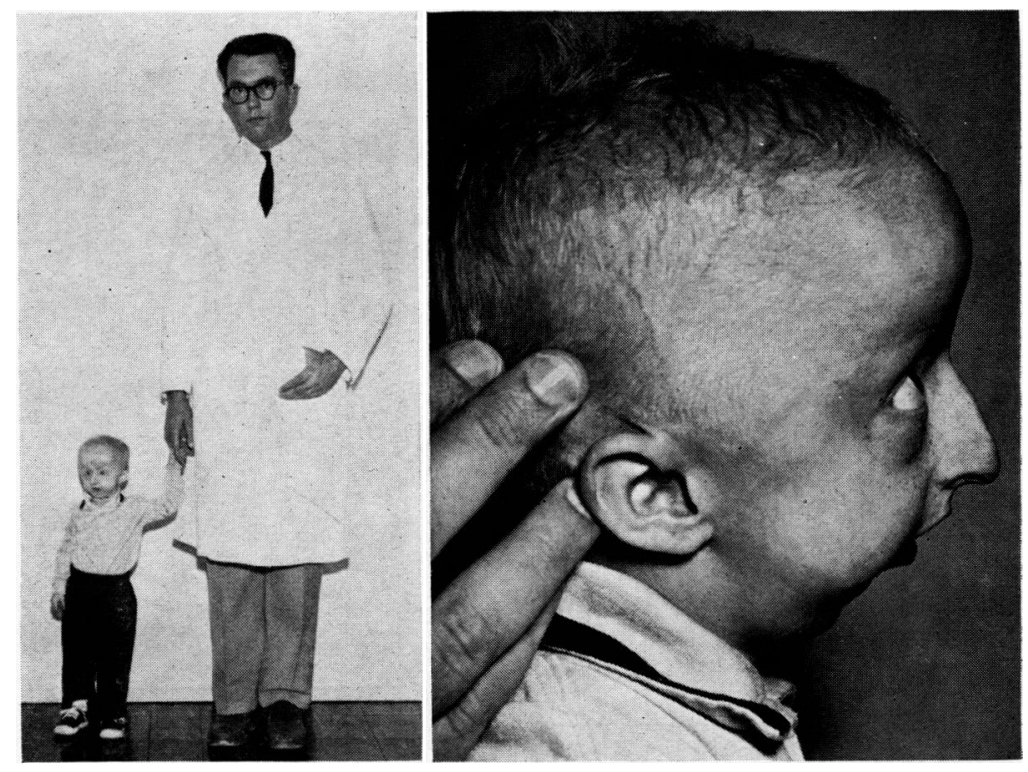

Fig. 3.-Case 2 at the age of $6 \frac{1}{2}$ years.

Fig. 4.-Close-up of head and face of Case 2 at the age of $6 \frac{1}{2}$ years.

FIG. 5.-Case 3 at the age of $2 \frac{1}{2}$ years.
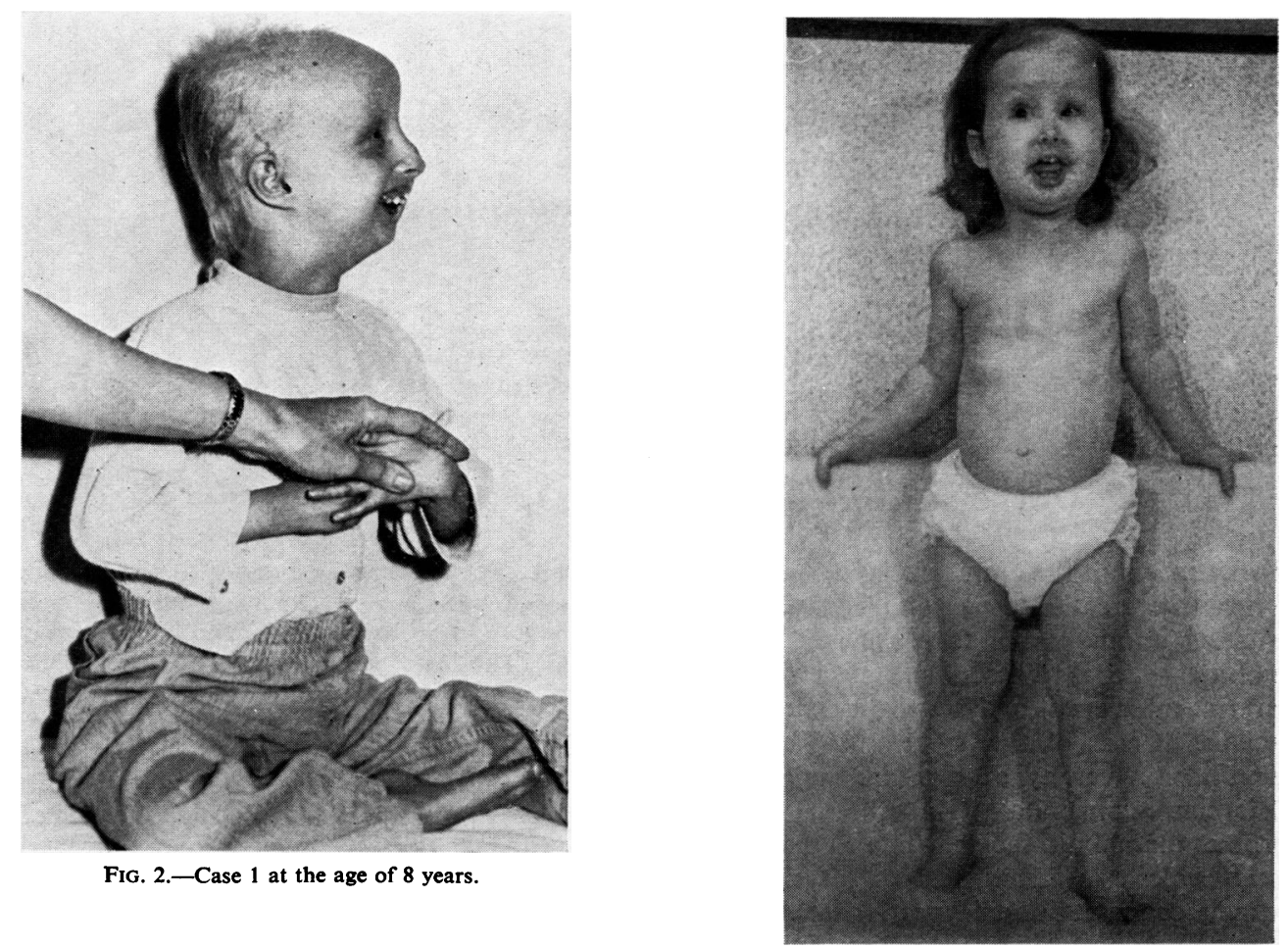

FIG. 2.-Case 1 at the age of 8 years. 
fontanelles were closed to palpation, but radiologically the anterior and posterior fontanelle were still open. The ears were low set. There was severe micrognathia with marked limitation of movement in both temporomandibular joints. The nose was beaked with a deviation of the nasal septum. The mouth was small and the palate had a high arch; the tongue was very small, but it moved normally. Twelve teeth were present, irregular in shape and implantation; the right upper central incisor was missing. The joints were hyperextensible, particularly in the elbows and knees. The reflexes were normal. The external genitalia were hypoplastic. The child drooled excessively, had no intelligible speech, could not walk, was not toilet-trained, and could not feed herself.

General laboratory studies of blood and urine were normal. Sex chromatin bodies were present in $5 \%$ of buccal smear cells and drumsticks in $2 \%$ of leucocytes. Short-term cultures of peripheral blood on three separate occasions showed a modal number of 46 chromosomes. Karyotypes of numerous metaphases were prepared and all these were normal.

$\mathrm{X}-1$ ay studies at the age of 7 years showed generalized osteoporosis of the skeleton. The anterior and posterior fontanelles were open, there was no platybasia, and the sella turcica and paranasal sinuses were normal. The orbits were small. The ascending ramus of the mandible was very small bilaterally and the temporo-mandibular joints were absent. Films of the wrists showed a bone age of 4 years.

There were four normal sibs, an older and a younger brother and sister; the mother had had one miscarriage between her first and second child.

Case 2. White male, examined at the age of 5 months because of slow growth and development. Bilateral cataracts were noted at that time and these were subsequently removed. Examination at the age of $6 \frac{1}{2}$ years showed a boy of diminutive proportions (Fig. 3) with a high-pitched, shrill voice and infantile behaviour; he was greatly handicapped by poor vision. He weighed $7 \cdot 5 \mathrm{~kg}$. and his height was $76 \mathrm{~cm}$. The brachycephalic skull measured $46 \mathrm{~cm}$. in circumference and showed prominent frontal bossing, while the anterior and posterior fontanelles were still open. There was sparse, thin blond hair limited to the posterior two-thirds of the skull. The nose was sharply hooked with a prominent deviation of the nasal septum. There was marked micrognathia (Fig. 4) and considerable symmetrical limitation of movement in the temporo-mandibular joints where no movement could be felt. The palate was highly arched and the tongue was thin and small. Many of the teeth, 16 in number, were irregular in shape. The following abnormalities were noted in the eyes: a constant searching, pendular nystagmus, blue sclerae, bilateral microphthalmus, and microcornea, absence of eyebrows, eyelashes, and lacrimal punctae; the tarsal plates could be felt and tears were present. Scrotum and penis were small, the latter showing a coronal hypospadias; no testes could be felt and there were no inguinal herniae. The joints were hyperextensible, particularly in the knees, leading to marked genu recurvatum. The reflexes were normal.

General laboratory studies of blood and urine were normal. At the age of 7 years the 24-hour output of 17-ketosteroids, determined on two separate occasions, was $810 \mu \mathrm{g}$. and $670 \mu \mathrm{g} . / 24 \mathrm{hr}$. X-ray studies showed a generalized osteoporosis of the skeleton, and films of the wrists showed a bone age of 2 years and 3 months. The anterior and posterior fontanelles were open, there was no platybasia, the sella turcica and paranasal sinuses were normal, and the orbits were small. The ascending rami of the mandible and the temporo-mandibular joints were absent.

There were no sex chromatin bodies in the cells of a buccal smear and no drumsticks in 200 leucocytes of peripheral blood. There were two older normal sisters, and the mother denied having had miscarriages.

Minor respiratory infections often led to marked obstruction of the upper respiratory tract; in addition the patient suffered from grass and weed pollinosis; this allergy was present in several members of the immediate family. At the age of 8 years, in the course of an illness with fever and coryza, the child acutely developed severe respiratory distress and died soon after admission to the hospital.

NECROPSY. The eyes were fixed with formalin immediately after death. Histological sections showed, in addition to the findings of post-operative aphakia, congenital focal tapeto-retinal adhesions in a region just nasal to the macula, characterized by proliferation of the pigment epithelium and focal gliosis of the outer layers of the retina. The optic nerves were normal. Pertinent findings of the general necropsy included a chronic bronchitis and oedema, and congestion and focal pneumonitis in the lungs. Both grossly and microscopically no testicular tissue could be found and only seminal vesicles and vasa differentia were identified with certainty. The lymphoid system, brain, endocrine glands, and the skin with appendages were normal.

Case 3. This girl was examined at the age of 3 months because of a pendular nystagmus in both eyes.

Examination showed bilateral cataracts, blue sclerae, microphthalmia and microcornea; the eyebrows were absent and the eyelashes sparse. Extracapsular cataract extractions were performed at the age of 10 months. Subsequent examination of the fundi showed the presence of punched-out areas of depigmentation with scalloped borders at the posterior poles of both eyes, involving the macular areas. There were numerous scattered hyaline dots within these areas of depigmentation, but there was no area of actual detachment.

The following additional findings were made at the age of $2 \frac{1}{2}$ years (Fig. 5): the skull was brachycephalic with a circumference of $37.5 \mathrm{~cm}$. and prominent frontal bossing. There was absence of hair growth over the frontal part of the skull with the anterior hairline approximately at the level of the coronal sutures. The nose was small and beaked with small nostrils, the mandible was underdeveloped, but movement in the temporo-mandibular joints was normal. The palate was highly arched and the tongue was of normal size. The teeth had erupted in a disorderly fashion. X-ray studies at the age of 2 years and 3 months showed a normal sella turcica, thick and 
short ascending rami of the mandible and normal temporo-mandibular joints. The orbits were small.

Minor respiratory infections caused much difficulty with breathing, because of the underdeveloped nasal structures. In the course of such an infection at the age of 3 years and 3 months, the child unexpectedly died. The pertinent finding at necropsy was a massive haemorrhagic bronchopneumonia and dilatation of the right side of the heart. No histological abnormalities were noted in other organs, including the brain. The eyes were not examined.

There were two other brothers and one older sister, the mother had not had any known miscarriages.

\section{Discussion}

An extensive review of the first 25 reported cases of dyscephalia mandibulo-oculo-facialis has been published by François (1958). Subsequently other cases have been described by Falls and Schull (1960), Calmettes, Déodati, Cadenat, and Béchac (1960), Bonamour and Léopold (1960), Carones (1961), van Balen (1961), Ponte (1962), and Manzitti and Alezzandrini (1963). It is evident from a survey of these reports that dyscephalia mandibulo-oculofacialis is to be regarded as a separate entity and that a variation in degree of the deformity exists, which not only concerns the principal anomalies of head and eyes, but also pertains to other features such as dwarfism and the retardation of motor and mental development.

The outstanding features of the syndrome are as follows: (1) abnormalities of the skull; (2) malformations of the face; (3) dental anomalies; (4) localized hypotrichosis; (5) congenital abnormalities of the eyes; (6) dwarfism; and (7) motor and mental retardation. The skull is brachycephalic in most instances, with a discrepancy in size of the large cranial vault and the small facial skeleton. By measurement, the head circumference can be normal or at the lower limits of normal. Prominent frontal and parietal eminences are present. The posterior fontanelle is frequently open at birth and remains so for a long time. The anterior fontanelle is large and remains patent well into childhood, as in our cases, or even later; in Case 6 of Falls and Schull (1960) the anterior fontanelle was still open at the age of 20 years. The sutures are usually widely open. The skin of scalp and face, especially over the nose, is white, thin, and tense with many small blood vessels readily visible. A striking feature is the diminished hair growth on the scalp. The hair is thin and sparse with areas of complete baldness; the latter either consists of patches of alopecia along the lambdoid and coronal sutures or, more typically, there is a complete baldness over the frontal area with an anterior border at the level of the coronal sutures.
Radiology of the cranial vault has shown in some cases the presence of a shallow sella turcica, platybasia or increased digital markings.

The ears are low set and, except for minor abnormalities of the ear-lobes, have a striking absence of deformities. In the majority of cases hearing is normal, but occasionally deafness is suspected (Bonamour and Léopold, 1960). The nose is small and beaked, with a sharp nasofrontal angle and often a deviation of the nasal septum. The narrow upper air passages lead to feeding difficulties in the newborn period and early infancy, and minor respiratory infections in later life cause obstruction, at times making tracheotomy necessary (van Balen, 1961; Falls and Schull, Case 3, 1960). The mouth is small with thin lips, and the palate is high arched. Fully erupted teeth at the time of birth are frequently present. The deciduous and permanent teeth erupt irregularly, are often malformed or sometimes absent altogether, especially one or more of the upper incisors. The zygomatic process is hypoplastic, but the most impressive change in the facial skeleton concerns the mandible and the temporomandibular joints. Clinically there is pronounced 'open bite', because of marked mandibular hypoplasia, while the deformities of the temporomandibular joints lead to limitation in opening the mouth. In some cases the temporo-mandibular joint is absent.

The most common anomalies of the eyes are bilateral microphthalmia, congenital cataract, ocular nystagmus, and strabismus. In several of the cases reported, spontaneous resorption of the cataracts occurred. In addition to these principal anomalies, many others have occurred in individual cases; these have been described by François (1960). In several cases in which the fundi have been inspected, degenerative disease of the retina has been noted such as chorioretinal atrophy or peripapillary choroid atrophy (Cases 2 and 3).

Bodily growth is severely retarded in most cases, resulting in a proportionate dwarfism with retarded bone age. Pubic and axillary hair are sparse to absent, the external genitalia under-developed and, in the males, the testes are commonly undescended or, when palpable, small in size. In Case 2 necropsy showed the testes to be absent. Hyperextensibility of joints, particularly in the knees, leading to genu recurvatum is commonly found. Motor, mental, and speech development are usually retarded, often profoundly so.

The family histories of most of the cases so far reported are incomplete. Consanguinity between parents has been reported in the first case of Manzitti and Alezzandrini (1963), but the degree of 
blood relationship is not mentioned. Familial occurrence has been reported by Larmande, as quoted by Manzitti and Alezzandrini (1963). Van Balen (1961) described the condition in two male twins, allegedly uniovular. With few exceptions, the pregnancies have been uncomplicated and fullterm, and the birth weights have been in the normal range. Birth order within sibships has not shown any particular trend and there has not been an unusual number of abortions in the reproductive histories of the mothers. Male and female cases have been reported with equal frequency. The ages of the parents are too infrequently mentioned to be of use in the evaluation of this factor. The patient of Ponte (1962), a woman with the syndrome in an unusually mild form, had given birth to two normal children.

Normal sex chromatin findings were reported in Case 6 of Falls and Schull (1960) and in the case of Bonamour and Léopold (1960). Carones (1961) has reported the results of cytogenetic studies in his case; cultures of fascia lata showed a normal modal number of chromosomes and in the karyotypes some discrepancy in size of two members of a pair of the 13-15 (D) group was noted. In our first case there was no structural abnormality observed in the chromosomes of the 13-15 group.

At first sight dyscephalia mandibulo-oculo-facialis is commonly confused with progeria (HutchinsonGilford), but the presence in the latter of a generalized atrophy of the skin and muscles, arthritis, early arteriosclerotic changes, and the absence of cataracts are some points of difference. Other entities with a superficial resemblance to the condition under discussion are mandibulo-facial dysostosis and cleidocranial dysostosis; François (1958) has given an extensive differential diagnostic tabulation.

\section{Summary}

Clinical and radiological findings are described in three cases of dyscephalia mandibulo-oculo-facialis (Hallermann-Streiff syndrome). This syndrome consists of abnormalities of the skull, malformations of the facial skeleton and jaws, dental anomalies, including the presence of erupted teeth at birth, localized hypotrichosis, congenital abnormalities of the eyes, dwarfism, and motor and mental retardation. The results of cytogenetic studies in one case and necropsy findings in two of the cases are reported.

We thank the following colleagues for clinical information and help in obtaining material for histopathological examination of Cases 2 and 3: Dr. E. Twible and Dr. W. Mosig, Springfield, Massachusetts; Dr. J. Giammalvo, Holyoke, Massachusetts; Dr. S. D. Liebman, Boston, Massachusetts; Dr. S. E. Wheelock, Hitchcock Clinic, Hanover, New Hampshire; Dr. H. Buckbee, Dolgeville, New York, Dr. W. R. Redline, Utica, New York, Dr. D. G. Cogan, Howe Laboratory of Ophthalmology, Boston, Massachusetts described the histopathology of the eye.

\section{REFERENCES}

Balen, A. Th. van (1961). Dyscephaly with microphthalmos, cataract and hypoplasia of the mandible. Ophthalmologica (Basel), 141, 53.

Bonamour, G., and Léopold, P. (1960). Syndrome dyscéphale avec tête d'oiseau (syndrome de François). Bull. Soc. Ophtal. Fr., p. 85

Calmettes, L., Déodati, P., Cadenat, H., and Béchac, G. (1960). La dysmorphie mandibulo-faciale type François (à propos d'un cas). Rev. oto-neuro-Ophtal., 32, 275.

Carones, A. V. (1961). Syndrome dyscéphalique de François. Ophthalmologica (Basel), 142, 510.

Falls, H. F, and Schull, W. J. (1960). Hallermann-Streiff syndrome. A dyscephaly with congenital cataracts and hypotrichosis. A.M.A. Arch. Ophthal., 63, 409.

François, J. (1958). A new syndrome. Dyscephalia with bird face and dental anomalies, nanism, hypotrichosis, cutaneous atrophy, microphthalmia, and congenital cataract. ibid., 60, 842.

- (1960). Syndromes with congenital cataract (XVI Jackson Memorial Lecture). Trans. Amer. Acad. Ophthal. Otolaryng., 64, 433.

Hallermann, W. (1948). Vogelgesicht und Cataracta congenita. Klin. Mbl. Augenheilk, 113, 315 .

Manzitti, E., and Alezzandrini, A. A. (1963). Syndrome dyscéphalique de François. Ann. Oculist. (Paris), 196, 456.

Ponte, F. (1962). Further contributions to the study of the syndrome of Hallermann and Streiff (Congenital cataract with 'Bird's Face'). Ophthalmologica (Basel), 143, 399.

Streiff, E. B. (1950). Dysmorphie mandibulo-faciale (tête d'oiseau) et altérations oculaires, ibid., 120, 79.

Ullrich, O., and Fremerey-Dohna, H. (1953). Dyskephalie mit Cataracta congenita und Hypotrichose als typischer Merkmalskomplex. ibid., 125, 73 and 144.

Waardenburg, P. J., Franceschetti, A., and Klein, D. (1961). Genetics and Ophthalmology, Vol. 1. Blackwell, Oxford. 